\title{
Pregnancy outcome following spontaneous abortions
}

\author{
Swati Agrawal*, Veena Agrawal, Rajni Suhane
}

Department of Obstetrics and Gynecology G R Medical College, Gwalior, MP, India

Received: 18 September 2015

Revised: 07 October 2015

Accepted: 28 October 2015

\section{*Correspondence:}

Dr. Swati Agrawal,

E-mail: drswati.agrawal@gmail.com

Copyright: () the author(s), publisher and licensee Medip Academy. This is an open-access article distributed under the terms of the Creative Commons Attribution Non-Commercial License, which permits unrestricted non-commercial use, distribution, and reproduction in any medium, provided the original work is properly cited.

\section{ABSTRACT}

Background: The objective of the present study was to study pregnancy outcome in patients with history of previous spontaneous abortions.

Methods: A prospective study included patients with history of previous spontaneous abortion admitted in the Department of Obstetrics and Gynaecology, GR Medical College and Kamla Raja Hospital, Gwalior between September 2008 and February 2009. The patients were either booked (minimum 3 visits in antenatal outdoor clinic) or admitted for the first time as an emergency. The detailed history about previous abortions was taken and routine as well as investigations for possible etiologies of previous abortions were done. Cases with history of mid-trimester abortion were investigated for cervical incompetence. All the patients were observed for complications during present pregnancy like threatened abortion, preeclampsia, preterm labour, intrauterine death and final outcome.

Results: A total of 70 patients with history of previous spontaneous abortion were admitted, out of which 40 (57.2\%) patients were booked and $30(42.8 \%)$ reported first time in emergency. Majority $(57.1 \%)$ of patients belong to the age group 21-29 years. Educational status of the patients showed $61.4 \%$ had no formal education or only up to primary level. Anemia was found to be very severe in $4.3 \%$, severe in $10 \%$ and moderate in $30 \%$ patients. Maximum patients $(45.7 \%)$ were with history of previous one abortion followed by previous two abortions $(38.6 \%)$. Incidence of abortions after one, two, three and four abortions was 9.4, 14.8, 20 and 100 percent respectively. The final outcomes were term live birth $(74.3 \%)$, abortion $(14.3 \%)$, preterm delivery $(8.6 \%)$, and still birth $(2.8 \%)$. In the present study $10(14.3 \%)$ pregnancies ended with abortion, out of which 4 were in booked and 6 in emergency patients. Live babies were of $90 \%$ booked mothers whereas $70 \%$ in emergency patients. Caesarian section was done in $23.3 \%$ patients for various indications.

Conclusions: Previous history of spontaneous abortion is associated with adverse pregnancy outcome. There is $\mathrm{i}_{\mathrm{ie}}$ increased risk of abortion, preterm delivery, need for caesarean sections and fetal loss in cases of previous 1, spontaneous abortions. These complications and fetal loss can be reduced by booking the patients and giving due antenatal care.

Keywords: Pregnancy, Spontaneous abortion, Preterm delivery, Still birth

\section{INTRODUCTION}

Spontaneous pregnancy loss or miscarriage (abortion before 24 weeks of gestation) occurs in 15\% of pregnancies. ${ }^{1}$ In India occurrence of spontaneous abortion in urban areas is high as compared to rural area. ${ }^{2}$ Risk of recurrent miscarriage (three back to back spontaneous
The definite cause for previous spontaneous abortion cannot be found in about half of cases in spite of thorough investigations. ${ }^{3}$ The main causes for recurrent abortions include anatomical disorders, hormonal abnormalities, genetic anomalies and thrombophilia. ${ }^{3}$ 
Previous abortion in a women increases risk of threatened abortion, preterm delivery, and fetal loss. ${ }^{4}$ These factors has to be considered when deciding for antenatal close observations and management of pregnancy in patients with history of previous spontaneous abortions. ${ }^{4}$

Studies have reported a favourable outcome with 70 - 80 $\%$ live birth with counselling and supportive care in patients with previous abortions. ${ }^{5}$

The present study aimed to examine the pregnancy outcome in patients with history of previous spontaneous abortions.

\section{METHODS}

The present study included 70 patients admitted in the Department of Obstetrics and Gynaecology, G R Medical College and Kamla Raja Hospital, Gwalior, India from September 2008 to February 2009. Patients with history of spontaneous abortion preceding present pregnancy irrespective of gravidity, first visit or booked were enrolled randomly. Detailed history regarding previous abortion was taken and examination was done focusing on information about previous abortion.

In addition to routine investigation like $\mathrm{Hb}$, ESR, TORCH, urine routine and microscopy, specific investigation like VDRL, blood urea, and fasting blood sugar were carried out. Each antenatal patient was vaccinated with tetanus toxoid in second trimester.

Patients who were found to be Rh negative and their husband to be Rh positive were specifically asked for any history of hydrops foetalis, neonatal jaundice or anti-D therapy, blood transfusion received in previous pregnancy. Patients with history of mid-trimester abortions were investigated for cervical incompetency.

\section{RESULTS}

Out of 70 patients, $40(57.2 \%)$ were booked and $30(42.8$ $\%)$ reported for first time in emergency. Out of total, 40 (57.1\%) patients belong to the age group 21-29 years, 17 $(24.3 \%)$ in age group $<20,12(17.2 \%)$ in age group 3035 and one patients had age of $>35$ years.

Educational status of the patients showed that $43(61.4 \%)$ had no formal education or only up to primary level, 19 $(27.2 \%)$ had attended high school and only $8(11.4 \%)$ were graduates.

Anemia was found to be very severe ( $\mathrm{Hb}<4 \mathrm{gm} \%)$ in $3(4.3 \%)$, severe ( $\mathrm{Hb} 4-6.9 \mathrm{gm} \%)$ in 7 (10\%) and moderate in ( $\mathrm{Hb} 7-10 \mathrm{gm} \%)$ 21(30\%) patients.

Out of 70 patients, $32(45.7 \%)$ were with history of previous one abortion, $27(38.6 \%)$ with previous two abortions, $10(14.3 \%)$ with previous three abortions.
Incidence of abortions after one, two, three and four abortions was $9.4 \%, 14.8 \%, 20 \%$ and $100 \%$ respectively. Further the incidence of abortion was more in emergency cases as compared to booked cases. The final outcome of all patients is shown in table 1 .

Mode of delivery was vaginal in $42(70 \%)$, instrumental delivery in $4(6.7 \%)$, and caesarian section was done in $14(23.3 \%)$ patients.

Table 1: Outcome of present pregnancy in patients with previous spontaneous abortion.

\begin{tabular}{|ccccc|}
\hline $\begin{array}{c}\text { Sr. } \\
\text { No. }\end{array}$ & $\begin{array}{c}\text { Pregnancy } \\
\text { Outcome }\end{array}$ & $\begin{array}{c}\text { Booked } \\
(\%) \\
(\mathbf{N}=40)\end{array}$ & $\begin{array}{c}\text { Emergency } \\
(\%) \\
(\mathbf{N}=30)\end{array}$ & $\begin{array}{c}\text { Total } \\
(\mathbf{N}=70)\end{array}$ \\
\hline 1 & Abortion & $\begin{array}{c}4 \\
(10)\end{array}$ & $\begin{array}{c}6 \\
(20)\end{array}$ & $\begin{array}{c}10 \\
(14.3)\end{array}$ \\
\hline 2 & Missed & 0 & 1 & 1 \\
& Abortion & $(0)$ & $(3.3)$ & $(1.4)$ \\
\hline 3 & Preterm & 6 & 0 & 6 \\
& Delivery & $(15)$ & $(0)$ & $(8.6)$ \\
\hline 4 & Term live & 30 & 21 & 51 \\
& birth & $(75)$ & $(70)$ & $(72.85)$ \\
\hline 5 & Still birth & 0 & 2 & 2 \\
& & $(0)$ & $(6.7)$ & $(2.9)$ \\
\hline
\end{tabular}

Data is expressed in no of patients $(\%), \mathrm{N}$; Total no of patients.

\section{DISCUSSION}

The present study was aimed to study pregnancy outcome in 70 patients with history of previous spontaneous abortions. A total $30(42.8 \%)$ patients came to the hospital for first time as an emergency for delivery and these cases helped to compare the outcome to that of booked cases (40). Maximum patients were in the age group of 21-29 years, it being the maximum reproductive period. Educational status of the patients showed that 43 $(61.4 \%)$ had no formal education or only up to primary level which is similar to the findings of Hemminki et al who showed that spontaneous abortion is more common in low educational status. ${ }^{6}$

Out of 70 patients, $55.7 \%$ patients had $\mathrm{Hb} \geq 10 \mathrm{gm} / \mathrm{dl}$ which is associated with reasonably good health and pregnancy outcome. Similar results were shown by Alizadeh et al.

It is well observed that risk of abortions increases with increasing number of previous pregnancy losses. The incidence of miscarriage was found to be $9.4 \%, 14.8 \%$, $20 \%$ and $100 \%$ after one, two, three and four abortion respectively, which is slightly higher than the findings of Clifford et al who reported miscarriage rate after three and four abortions to be $29 \%$ and $27 \%$ respectively. ${ }^{5}$

Sheiner et al in their study of 7503 patients of recurrent abortion demonstrated higher risk of complications like abruptio placenta, hypertensive disorders and cesarean 
section. In another study of women with 3 or more miscarriages Reginald et al reported higher rates of small for gestational age babies, preterm deliveries and perinatal mortality. ${ }^{8}$

In our study, $35.8 \%$ patients showed different complications like threatened abortion, pre-eclampsia, antepartum hemorrhage, preterm labour and intrauterine death. The abortions and still birth were more in emergency patients as compared to booked patients (Table 1).

Studies had shown a significant association between recurrent abortions and caesarean sections (CS) even after controlling the confounders. ${ }^{3}$ In our study CS was done in $23.3 \%$ patients for various indications. Incidence of operative and instrumental delivery was high so as to avoid maternal exhaustion, prolonged second stage of labour and fetal distress.

It has been established that supportive care and antenatal checkups improves the pregnancy outcome. In our study live fetuses were delivered by $90 \%$ booked mothers whereas it reduced to $70 \%$ in patients who presented for the first time to the hospital, which is similar to the findings of Clifford et al. ${ }^{5}$

To conclude, patients with previous history of spontaneous abortion are associated with adverse pregnancy outcome. The complications and fetal loss can be reduced by booking the patients and giving due antenatal care.

\section{CONCLUSIONS}

Serial sweeping of the membranes is both safe and effective in the prevention of pregnancy beyond 41 weeks and hence reduces the incidence of post-term pregnancy, its risks and the related costs in uncomplicated pregnancies.

Funding: No funding sources

Conflict of interest: None declared
Ethical approval: The study was approved by the Institutional Ethics Committee

\section{REFERENCES}

1. Brigham SA, Conlon C, Farquharson RG. A longitudinal study of pregnancy outcome following idiopathic recurrent miscarriage. Human Reproduction.1999; 14(11):2868-71.

2. Maharana B. Correlates of Spontaneous and Induced Abortion in India: An Investigation using a Nationwide Large Scale Survey Data.

3. Sheiner E, Levy A, Katz M, Mazor M. Pregnancy outcome following recurrent spontaneous abortions. European Journal of Obstetrics \& Gynecology and Reproductive Biology. 2005;118:61-5.

4. Agrawal S, Khoiwal S, Jayant K, Agarwal R. Predicting adverse maternal and perinatal outcome after threatened miscarriage. Open Journal of Obstetrics and Gynecology. 2014;4:1-7.

5. Clifford K, Rai R, Regan L. Future pregnancy outcome in unexplained recurrent first trimester miscarriage. Human Reproduction. 1997;12(2):3879.

6. Hemminki E, Forssas E. Epidemiology of miscarriage and its relation to other reproductive events in Finland. Am J Obstet Gynecol. 1999;181(2):396-01.

7. Alizadeh L, Raoofi A, Salehi L, Ramzi M. Impact of Maternal Hemoglobin Concentration on Fetal Outcomes in Adolescent Pregnant Women. Iran Red Crescent Med J. 2014;16(8):1-5.

8. Reginald PW, Beard RW, Chapple J, Forbes PB, Liddle HS, Mowbray JF. Outcome of pregnancies progressing beyond 28 weeks gestation in women with history of recurrent miscarriage. $\mathrm{Br} \mathrm{J}$ Obstet Gynecol. 1987;94:643-8.

Cite this article as: Agrawal S, Agrawal V, Suhane R. Pregnancy outcome following spontaneous abortions. Int J Reprod Contracept Obstet Gynecol 2015;4:1891-3 